\title{
PERSPECTIVE
}

\section{Gendered Expectations: Do They Contribute to High Burnout Among Female Physicians?}

\author{
Mark Linzer, $M D^{7}$ and Eileen Harwood, $\mathrm{PhD}^{2}$ \\ 'Division of General Internal Medicine, Office of Professional Worklife, Hennepin County Medical Center, Minneapolis, MN, USA; ${ }^{2}$ School of Public \\ Health, University of Minnesota, Minneapolis, MN, USA.
}

Patients have differing expectations of female versus male physicians. Female patients tend to seek more empathic listening and longer visits, especially with female physicians; however, female doctors are not provided more time for this. Female doctors have more female patients than male doctors, and more patients with psychosocial complexity. We propose that gender differences in patient panels and gendered expectations of female physicians may contribute to the high rate of burnout among female clinicians, as well as to the many female physicians working part-time to reduce stress in their work lives. We propose several mechanisms for addressing this, including brief increments in visit time (20, 30 and $40 \mathrm{~min})$, staff awareness, training in patient expectations during medical school, adjusting for patient gender in compensation plans, and co-locating behavioral medicine specialists in primary care settings. Beneficial outcomes could include fewer malpractice suits, greater patient satisfaction, higher quality care, and lower burnout among female physicians.

KEY WORDS: burnout; disparities; patient satisfaction; physician behavior; psychosocial.

J Gen Intern Med 33(6):963-5

DOI: $10.1007 / \mathrm{s} 11606-018-4330-0$

(c) Society of General Internal Medicine 2018

Ann sees Dr. Mary the day she wants to talk about numerous psychosocial issues; she has several issues to raise that would require a long visit and would benefit from empathic listening. Ann is a complex patient with both medical and psychosocial problems. Dr. Mary tries to listen, but becomes pressed for time and unfortunately needs to cut Ann off several minutes into the appointment. Expecting to have had more time with Dr. Mary, Ann rates her as lacking sufficient listening skills on the patient satisfaction survey.

Jonathan has a visit with Dr. Dave. He has some psychosocial issues, but is not eager to bring them up. Furthermore, he does not expect Dr. Dave to spend much time listening. The doctor does not ask about the

Received September 1, 2017

Revised November 21, 2017

Accepted January 10, 2018

Published online February 12, 2018 psychosocial issues. The appointment ends after a few minutes and Jonathan says nothing about his concerns. Because his expectations were met during the visit, Jonathan gives Dr. Dave a good score on the patient satisfaction survey.

These representational scenarios demonstrate the challenges for female physicians related to their patients' gendered expectations. In general, patients differ by gender in their expectations regarding doctor-patient relational interactions. Roter and Hall have shown that patients of female physicians spoke more during office visits and disclosed more biomedical and psychosocial issues. Because female physicians also asked more psychosocial questions, appointment duration was $10 \%$ longer for female physicians compared to males. ${ }^{1}$ Houle, Harwood, and colleagues assessed "what women want" during visits with their health care providers. ${ }^{2}$ The authors found that women had high hopes for empathic care that they associated with being listened to. These types of expectations may have negative consequences that disproportionately affect female physicians.

Potential Connection Between Burnout and Patient Expectations. An early study of physician work-life demonstrated a $60 \%$ excess of burnout in females versus male physicians. This excess burnout appeared to be driven, in part, by uneven patient expectations affecting not only office visits, but also physician work lives and personal wellness. ${ }^{3}$ In this study, female physicians had more female patients and more patients with psychosocial complexity; thus, the patients of female physicians had, on average, different needs (such as gynecologic care and counseling) and required longer visits. In an experimental design study, female participants were more likely than males to express satisfaction with their simulated doctor's visits when the female physician's communication style was caring, while it did not matter whether the male physician demonstrated a caring communication style. ${ }^{4} \mathrm{~A}$ study of perceived dominance found that both male and female participants perceive female physicians as dominant, significantly more so than male physicians, when they sit too close, speak more and/or loudly, look more often at their computer, ask too many questions, or disagree with patients. ${ }^{5}$

Cousin and colleagues recently showed that patients tolerated expressed uncertainty from their physicians except in 
"male patient: female doctor" dyads; in these instances, patient satisfaction fell precipitously when female physicians told male patients, "I don't know." In contrast, Macrae ${ }^{7}$ showed that female patients tend to want their doctors (preferably female) to be empathic and to be able to say "I don't know". Female physicians are thus subjected to gendered stereotypes and expectations with hidden rules for appropriate behavior. ${ }^{8}$ Identifying and adhering to these rules can be both unsettling and stressful. Puffer and colleagues recently found a higher rate of burnout among female family physicians. ${ }^{9}$ Thus, while a link between burnout and expectations is not proven, uneven expectations seem an important clue to investigate as we seek to decrease burnout.

Practice Style Differences. Studies have shown that female physicians tend to follow clinical guidelines more often, provide more preventive care, and give more counseling than their male counterparts. ${ }^{10}$ They also score higher on empathy scales, use more egalitarian language, and use less technical jargon when speaking with patients. ${ }^{8,} 11$ Consequently, patients of female physicians appear to obtain better patient outcomes, with lower readmission and mortality rates among the patients of female versus male hospitalists. ${ }^{10}$

Conceptual Framework. A conceptual model linking these variables, based in part on results from the physician work-life study, ${ }^{12}$ connects gendered expectations and differing practice styles to key work-life variables (time pressure during visits, an increasingly hectic work pace, excess work hours, and workhome interference). These work conditions can affect satisfaction, stress, and burnout and ultimately lead to greater personal challenges in achieving excellent patient outcomes (see Fig. 1).
We propose this model for further analysis and investigation. The model can help to explain, for example, why many women physicians choose part-time work as a means of reducing excess work hours and work home interference. It also shows how addressing gendered expectations could reduce time pressure during office visits and thus improve work-life and burnout. This would potentially allow for improving patient outcomes even further, at less personal cost to the female physician.

Proposed Mechanisms for Improvement. A first step is to build provider and health system awareness about these situations. Knowing more about patterned variations in patient expectations can shape responsive and appropriate behavior from physicians (i.e., "Let's book a longer visit next time to allow more time for discussion.") and clinic scheduling staff (i.e., "Will you need a short or longer appointment to discuss your concerns with the doctor?"). These options will work for female or male physicians who need more listening time for their patients. The excess work of listening, counseling, and preventive care may add an extra 5-10 min to a typical visit. Thus, shorter increments in visit length (e.g., with 20 and $30 \mathrm{~min}$ choices, rather than only 20 and $40 \mathrm{~min}$ options) would allow slightly longer visits for patients with psychosocial concerns, gynecologic care, or a need to coordinate care. Appropriate reimbursement for these longer visits can be sought by coding for time spent counseling and coordinating care. Training in professionalism and communication skills during medical school, residency, and fellowship ${ }^{13}$ could make it easier for physicians of both genders to connect with patients and rectify gender-related dynamics that disadvantage women physicians. Training could also prepare women physicians to better anticipate and address these gender-associated dynamics when they occur.

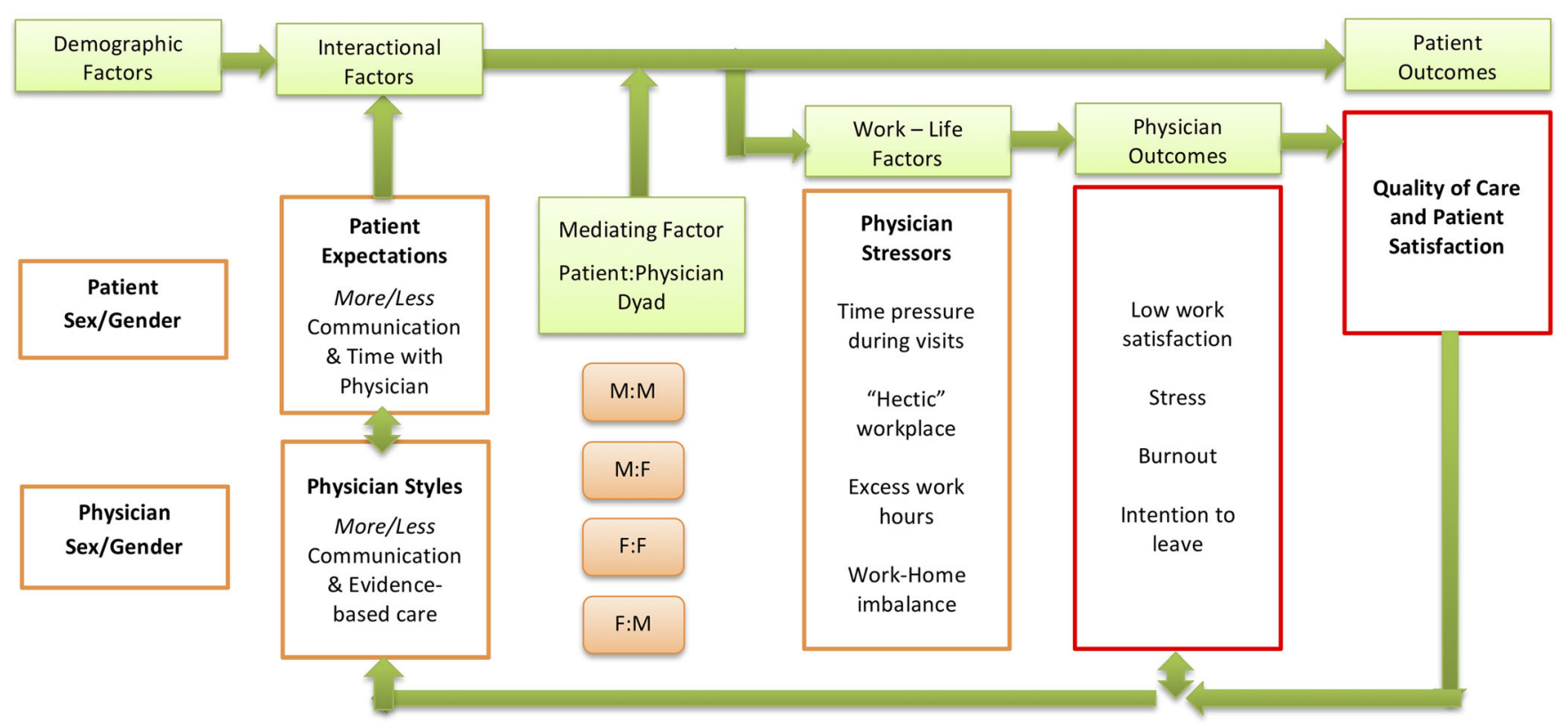

Fig. 1 Conceptual model linking gender to differences in physicians' and patients' expectations, experiences, and outcomes. 
Awareness can also allow us to build into our clinical infrastructures more equitable workflows and incentive systems. At one midwestern university, the physician compensation plan adjusted for numbers of female patients, i.e., if a doctor saw more female patients, her or his panel size was adjusted by $10 \%$ to accommodate the extra time these patients may require due to their medical and psychosocial complexity. ${ }^{14}$ Another solution is to acknowledge patients' behavioral medical needs and to co-locate behavioral medicine colleagues to share the care of these complex patients. ${ }^{15}$

Anticipated Outcomes. Numerous beneficial outcomes have been described, although few have been formally tested. Fewer malpractice suits are recorded for female compared to male physicians. ${ }^{16}$ Thus, allowing sufficient time for more favorable physician-patient communication could reduce lawsuits in female and male physicians. Patient satisfaction is likely to quickly improve when sufficient time is allotted for connection, empathy, and listening. Lower time pressure and reduced chaos are known to relate to enhanced provider satisfaction with reduced burnout and turnover. ${ }^{17}$ Finally, improved patient outcomes can be expected due to improved adherence to medications from greater patient understanding. ${ }^{18}$ As these studies did not specifically measure the impact of addressing gendered expectations, we encourage future research in these critical areas to evaluate the magnitude of the outcomes for physicians and patients.

Implications. These findings may not seem new to female physicians, and, indeed, have been building within the medical literature for over 15 years. But, as burnout among female physicians remains high, these data and perspectives provide a set of potential ways forward in achieving greater gender equity in physician work-life. We therefore hope that this information will be useful in the following ways:

(1). empowering for female physicians to know there are data to support their lived experiences,

(2). illuminating for male physicians, medical directors, and clinic managers that the "caring field" is not level and requires adjustment, and

(3). motivating for health system leaders and insurance plans to cost-effectively address the quadruple aim of excellent outcomes for providers and patients by avoiding costly burnout and turnover $(\$ 250,000-\$ 500,000$ for each departing physician ${ }^{19,20}$ ) and thus improve quality of care and enrollee satisfaction.

We welcome readers, clinicians, and scholars into this discussion and this field of study.

Acknowledgements: The authors gratefully acknowledge the contributions of Sara Poplau and the librarians at Hennepin County Medical Center, Danielle A. Becker and Paul A. Reid, who provided numerous key references that explained and supported the central thesis in our paper.

This work has not been presented elsewhere.

Corresponding Author: Mark Linzer, MD; Division of General Internal Medicine, Office of Professional Worklife, Hennepin County Medical Center, Minneapolis, MN, USA (e-mail: Mark.Linzer@hcmed.org).

\section{Compliance with ethical standards:}

Conflict of interest: The authors declare that they have no conflict of interest.

\section{REFERENCES}

1. Roter D, Hall J. Physician gender and patient-centered communication: a critical review of empirical research. Annu Rev Public Health. 2004;25:407-519.

2. Houle C, Harwood E, Watkins A, Baum KD. What women want from their physicians: a qualitative analysis. J Women's Health. 2007;16:543-50.

3. McMurray JE, Linzer M, Konrad TR, et al. The work lives of women physicians: results from the physician work life study. J Gen Intern Med. 2000;15:372-80.

4. Mast MS, Hall JA, Roter DL. Disentangling physician sex and physician communication style: their effects on patient satisfaction in a virtual medical visit. Patient Educ and Counseling. 2007;68:16-22.

5. Mast MS, Hall JA, Klockner Cronauer C, Cousin G. Perceived dominance in physicians: are female physicians under scrutiny? Patient Educ and Counseling. 2011;83:174-79.

6. Cousin G, Mast MS, Jaunin-Stalder N. When physician-expressed uncertainty leads to patient dissatisfaction: a gender study. Med Educ. 2013;47:923-31.

7. Macrae H. Not too old, not too young: older women's perceptions of physicians. Canadian J Aging. 2015;34:545-60.

8. Kilminster S, Downes J, Gough B, Murdoch-Eaton D, Roberts T. Women in medicine-is there a problem? A literature review of the changing gender composition, structures and occupational cultures in medicine. Med Educ. 2007;41:39-49.

9. Puffer JC, Knight HC, O'Neill TR, et al. Prevalence of burnout in boardcertified family physicians. J Am Board Fam Med. 2017;2:125-6.

10. Tsugawa Y, Jena AB, Figueroa JF, Orav J, Blumenthal DM, Jha AK. Comparison of hospital mortality and readmission rates for Medicare patients treated by male versus female physician. JAMA Intern Med. 2017;177:206-13.

11. Howick J, Steinkopf L, Ulyte A, Roberts N, Meissner K. How empathic is your healthcare practitioner? A systematic review and meta-analysis of patient surveys. BMC Med Educ. 2017;17:136.

12. Linzer M, Visser MR, Oort FJ, Smets EM, McMurray JE, de Haes HC. Society of General Internal Medicine (SGIM) Career Satisfaction Study Group. Predicting and preventing burnout: results from the United States and the Netherlands. Am J Med. 2001;111(2):170-5.

13. Turner DA, Fleming GF, Winkler M, et al. Professionalism and communication education in Pediatric critical care medicine: the learner perspective. Acad Pediatrics. 2015;15:380-85.

14. Trowbridge E, Bartels C, Koslov S, Kamnetz S, Pandhi N. Development and impact of a novel academic primary care compensation model. J Gen Intern Med. 2015;30:1865-70.

15. Linzer M, Popkin MK, Coffey E. The Hennepin County Medical Center program in Medical Psychiatry: addressing the shortened lifespan of patients with mental illness. J Gen Intern Med. 2013:28(3):466-9.

16. Unwin E, Woolf K, Wadlow C, Potts HW, Dacre J. Sex differences in medico-legal action against doctors: a systematic review and metaanalysis. BMC Medicine. 2015;13(1):172.

17. Linzer M, Manwell LB, Williams ES, et al. Working conditions in primary care: physician reactions and care quality. Ann Intern Med. 2009;151(1):28-36.

18. Bodenheimer T, Sinsky C. From triple to quadruple aim: care of the patient requires care of the provider. Ann Fam Med. 2014;12(6):573-6.

19. Buchbinder SB, Wilson M, Melick CF, Powe NR. Estimates of costs of primary care physician turnover. Amer J Manag Care. 1999;(11):1431-8.

20. Schloss EP, Flanagan DM, Culler CL, Wright AL. Some hidden costs of faculty turnover in clinical departments in one academic medical center. Acad Med. 2009;84(1):32-6. 